\title{
Offering Minority Communities Equal Opportunities Through Entrepreneurship
}

Dr. Thomas M. Cooney

Dublin Institute of Technology, Ireland

Keywords

- Minority Entrepreneurship

- Ex-Prisoners

- Disabled People

- Travellers/Gypsies

- Grey and Gay

\begin{abstract}
A substantial body of research has been undertaken in recent years giving prominence to the additional and distinctive challenges faced by female entrepreneurs and by ethnic entrepreneurs. However, other groups of minority entrepreneurs have received relatively little attention and so remain underexplored within entrepreneurship literature. This article introduces some of these minority communities (Ex-Prisoners, Disabled People, Travellers/Gypsies, Grey and Gay) and highlights the research opportunities that exist for entrepreneurship academics who might wish to analyse such 'silent' minorities. These communities are all relatively large in terms of population numbers, require tailored support to overcome distinctive economic, social and personal obstacles, and would benefit from critical appraisals of their circumstances.
\end{abstract}

